\title{
The application of remote sensing data for the assessment of man-made environments in the coal regions of the south of the Far East
}

\author{
Marina Bubnova ${ }^{1 *}$ \\ ${ }^{1}$ Mining Institute of Far eastern branch of Russian Academy of Sciences, Khabarovsk, Russia.
}

\begin{abstract}
The paper is concerned with analysis state of surfaces of waste dumps coal deposits according to Earth remote sensing. It is noted, that formed because of open-pit operations at Bikinsky and Raichikhinsky coal mining enterprise areas denudation accumulative violations were determinate by using programs for satellite images interpretation, as well as certain large forms of man-made relief (such as quarries, dumps, sedimentation tanks) were identified, followed by the calculation of their areas and the assessment of the value of environmental and economic damage to the environment, i.e. it was possible to give not only a qualitative description of the pollution process, but also its quantitative assessment. The approach to biomass determination based on vegetation NDVI index is presented. The conclusion is based on possibility of selfrestoration of the plant ecosystem on the surface of mining landscapes without special work on the reclamation of disturbed lands. Key words: Dumps of coal enterprise, remote sensing of the Earth, satellite images, vegetation indices, self-growth
\end{abstract}

\section{Introduction}

The use of earth remote sensing data is currently almost the only opportunity to obtain objective and reliable information about the state of mining landscapes in large areas.

In the mining industry, land degradation as a result mining of deposit is one of the biggest problem. For example, on south of the Far East, a significant amount of disturbed land is the result of the use of open methods of mining, in particular brown coal. At the same time, stripping and containing rocks are transferred to the surface. Non-selective (gross) spallation leads to a chaotic mixing of rocks that differ in granulometric, petrographic, mineralogical compositions. Most of the dumps remain under self-growth and are not reclaimed [1].

Dumps are accumulative forms of techno-relief of different heights and occupied area. Their dimensions often do not go beyond the mesoforms of the relief with an aligned flat top, in the profile having a trapezoidal shape. Physically, the miming dump is a complex structure: the top, from where the small particles and nutrients flush away, the transit zone is the slopes through which the small particles of the rock are transported to the foot of the

${ }^{*}$ Corresponding author: 138 marina@mail.ru 
dump, called the accumulative zone. Here the substances washed away from the top accumulate, so that more favorable conditions are created for the beginning of the process of soil cover restoration [2].

The study of the processes of overgrowing dumps of coal deposits in the southern Far East and their reclamation are devoted to the work of a number of authors: Gusachenko A. Yu., 1992; Krupskaya L. T., 1992; Kurachev V. M. and E. R. Kondrashin, 1994; Radaev V. V., 2004; Kostenkova N. M. and Sabihin V. I., 2007 etc. In these works the main attention was paid to the issues of restoring economic functions of the disturbed mining areas [3-5]..

When solving the problems of assessing the territories of dumps of coal enterprises, a number of issues often arise that are associated with the definition of the boundaries of objects, the allocation of the class of pollutants, the definition of the impact of pollution on vegetation/soil, the detection of zones of deformation of the earth's surface. Earth remote sensing (ERS) technologies provide unique tools for solving such problems. The use of space images in the monitoring of the environment in the areas of coal mining allows you to monitor the pollution of the water basin, to analyze the state of vegetation, to identify the degradation of soil, thus solving the following tasks: a) determining the impact on the environment; b) assessment of pollution; c) determining the boundaries and deformation zones of anthropogenic objects. This article describes some examples of the use of remote sensing data for the assessment of man-made situations in the coal regions of the South of the Far East.

\section{Materials and methods researches}

Modern technical means of remote sensing of the Earth (ERS), allow obtaining digital images of areas of the earth's surface with high spatial resolution and in a wide range of electromagnetic waves. In addition, mathematical methods for processing digital images (spatial-spectral analysis, coverage of the territory, registration of a sufficiently wide range of electromagnetic spectrum, regular observation of the territory, free access and convenient interface for downloading archives), which can be applied with appropriate adaptation of the algorithmic base processing of digital images of the soil cover of coalmining areas [6].

The study assessed the spread of soil cover contamination and its self-repair in various mining regions via Landsat satellite images (NASA USA), which is freely available on the USGS website. During the work, the images were downloaded, their selection, the choice of informative ranges of the electromagnetic spectrum [6].

The main working tool for solving the problems of this study was the computer application QGIS (Quantum GIS), which is distributed over the Internet under the license Open GPL [7]. Criteria for its selection in the composition with GRASS GIS were multitasking, multiplatform, extensibility and relatively easy learning opportunities. As a topographic basis, was used the Russian edition vector map Open Street Map, which is freely accessible on the Internet [8]. Separate areas were detailed and refined according to the Cadastral map of the Russian Federation.

From the Internet, digital elevation models (DEM) were downloaded: regular matrices with a sampling rate of $1000 \mathrm{~m}$ (SRTM30) and $90 \mathrm{~m}$ (SRTM03) and inserting them into a GIS [9]. Combining satellite images with DEM allows you to get a visual representation of mining facilities on the ground, i.e. to build a digital model of the area under investigation [6]. Due to this, it becomes possible to assess the features and character of the distribution of pollutants in mining areas and the factors that influence this distribution. 


\section{Results and discussion}

On the example of Bikinsky and Raichikhinsky brown coal deposits, an assessment was made of the degree of disturbance of the surface of the mining areas by mine workings. The studies were carried out by methods of remote satellite monitoring of the Earth's surface on the basis of an analysis of spatio-temporal variability of the formed pioneer plant groups.

Bikinskoye brown-coal deposit is located in the north-western part of Primorsky Territory. Disposal external: of the total volume of overburden approximately $1 / 3$ is placed in the internal dumps at the horizon of the lower coal seam to be mined and the remainder is transported to external dumps (fig. 1).
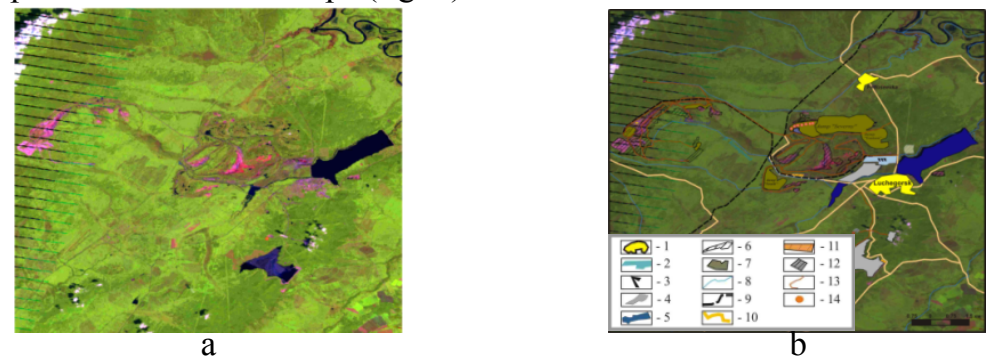

Fig. 1. Bikinskoye brown-coal field: a-Multichannel satellite image obtained from the us earth remote sensing satellite Landsat 7 in a combination of spectral channels 4-5-1 from 07.08.2009; b-Maps of the spatial structure of the district of Bikinskoye brown-coal field, with the allocation of man-made objects, based on the decoding of satellite images: 1-settlements; 2-technical complex of the Primorskaya power plant; 3-boilers, boiler emissions into the atmosphere; 4-ash dumps; 5-pondcooler GRES; 6 - coal pits; 7 - rock dumps; 8 - river network; 9 - Railways; 10 - roads; 11 - auxiliary production; 12 - LLC "Ecomed"; 13-roads; 14-dump sampling points

In QGIS in a rectangular projection EPSG - WGS 84 were measured area of the dumps shown in the picture (fig. $1 \mathrm{~b}$ ). The area occupied by the rock dumps at the Bikin brown-coal Deposit was $14.54 \mathrm{~km}^{2}, 12.34 \mathrm{~km}^{2}$ was occupied by coal mines, and $8.44 \mathrm{~km}^{2}$ by ash dumps, the mileage of coal roads was $88.87 \mathrm{~km}$. Total area of disturbed lands in 2009 was $35.32 \mathrm{~km}^{2}$, which is $65 \%$ of the allotted land. The calculation of ecological and economic damage to the environment by disturbed lands was made, which was carried out according to the formula:

$$
\operatorname{Ddl}=\sum_{i=1}^{n} \mathrm{~B}_{\mathrm{i}} \times \mathrm{S}_{\mathrm{i}} \text {, rub. }
$$

where: $\mathrm{n}$ - the number of types of disturbed land; $\mathrm{i}$ - type of disturbed land; $\mathrm{Si}$ - the area of disturbed lands of the $\mathrm{i}$-th type; $\mathrm{Bi}$ - the magnitude of the annual economic damage caused to the environment by i-type disturbed land. Value of the damage, inflicted to the environment disturbed lands is determined from Techniques of determining the economic efficiency of recultivation of disturbed lands [10].

$\mathrm{Ddl}=(270 \times 1454)+(65 \times 1234)+(185 \times 844)=628930 \mathrm{rub}$.

The magnitude of the ecological and economic damage from the area of disturbed lands of 3,532 hectares at the Bikinsky brown coal deposit amounted to 628930 rub.

Raychikhinskoe brown-coal field, is located in the southern part of the Amur region, near the town of Raichikhinsk. Area of the field is $50 \mathrm{~km}^{2}$. The city Raichikhinsk and settlements is almost entirely surrounded by or located next to the dumps, havings a height of 10 to $55 \mathrm{~m}$ (fig. 2). Due to this, a peculiar in the form of trench microrelief is created in the city. The use of remote sensing has made it possible to determine the areas of man-caused disruptions at the Raichikhinsky brown-coal field, from them: the area of waste heaps amounted to 11609 hectares, coal sections of 1895 ha and sumps an area of 184 hectares. The total area of disturbed land is 13688 hectares. 
According to formula 1, the calculation of environmental and economic damage to the environment by disturbed lands was carried out for Raichikhinsky brown-coal field:

$\mathrm{Ddl}=(65 \times 1895)+(185 \times 11609)+(21 \times 184)=2274704 \mathrm{rub}$.

The magnitude of the ecological and economic damage amounted to 2274704 rubles.

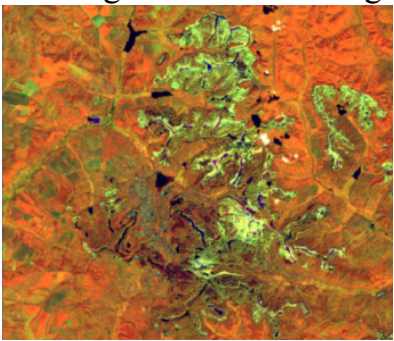

a

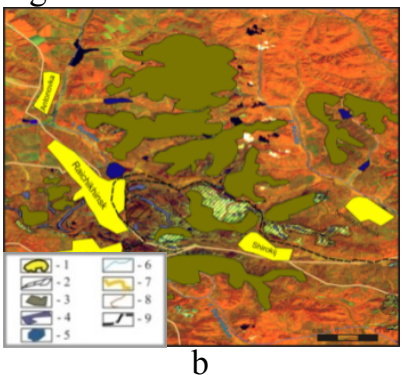

b

Fig. 2. Raychikhinskoe brown-coal field: a-Multichannel satellite image obtained from the us earth remote sensing satellite Landsat 7 in a combination of spectral channels 5-6-2 from 07.09.2013; b Maps of the spatial structure of the district of Raychikhinskoe brown-coal field, with the allocation of man-made objects, based on the decoding of satellite images: 1 - settlements; 2 - coal mines, 3 overburden dump; 4 - settlers $\% 5$ - pit; 6 lake; 7 - river, 8 - highway; 9 - coal road 10 railway road

Thus, with the use of materials for interpretation of space images, was recognized the area of denudation and accumulation of violations of, educated in open coal mining in Bikinsky and Raychikhinsk coal mines, and also identified some large forms of man-made terrain (such as quarries, dumps, sedimentation tanks), followed by the calculation of their areas and the assessment of the environmental and economic damage caused to the environment, i.e. it is possible to give not only a qualitative description of the pollution process, but also its quantitative assessment.

For most problems associated with the study and monitoring of both natural and manmade objects, it is convenient to use their physical characteristics, reconstructed from remote observation data. The greatest interest in our research is represented by vegetative and soil indices. Knowledge of the relationship between the structure and the state of vegetation with its reflective abilities makes it possible to use space images to identify the species composition of vegetation and its quality. A characteristic feature of vegetation and its state is the spectral reflectivity, characterized by large differences in the reflection of radiation of different wavelengths. Various normalized vegetative indices allow to calculate and estimate the volume of biomass in plant systems. The most sensitive spectral channel for counting this type of index is the "extreme red" red-edge range (705-745 nm) [11]. Soil indices characterize the degree of coverage of the observed surfaces by vegetation, and react well to the minimal presence of biomass on the surface of the object. Vegetation is very sensitive to environmental disturbances and most clearly reflects the change in the ecological situation as a result of technogenic impact. The state of vegetation can be considered as an indicator of the level of man-caused stress on the natural environment of the study area. Restoration of vegetation characteristics based on remote sensing data allows obtaining some numerical characteristics of the biomass volume, which can serve as an indicator of the restoration of disturbed lands.

The most popular and often used vegetation index - NDVI (Normalized Difference Vegetation Index). The high chlorophyll content associated with a large phytomass of vegetation leads to lower values of reflection coefficients in the red zone of the spectrum and greater values in the near infrared [12]. The value of the index directly depends on the photosynthetic activity of the vegetation and corresponds to its density at a certain point in the image, which is equal to the difference in the intensities of the reflected light in the red and infrared range divided by their sum. Calculated by the following formula: 
$\mathrm{NDVI}=(\mathrm{NIR}-\mathrm{RED}) /(\mathrm{NIR}+\mathrm{RED})$,

где NIR - the reflection in the near infrared region of the spectrum, RED - reflection in the red region of the spectrum.

NIKE and RED's attitude to each other allows us to clearly separate vegetation from other natural objects in the pictures. Figure 3 shows an example of the result of calculating NDVI for the territory of Luchegorsky district.

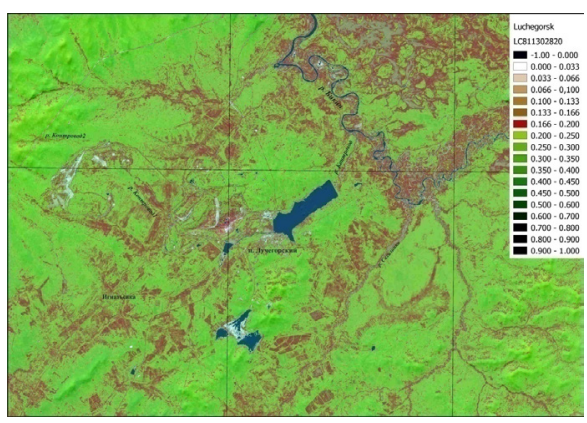

Fig. 3. Combining the NDVI with the digital model of the relief of the location area of the Luchegorsky coal mine

The average value of the index on this territory varies from 0.16 to 0.25 , which indicates the appearance of biomass on the surface. The amount of green biomass was influenced not only by anthropogenic factors (violation of the hydrogeological regime, in particular, the formation of a depression funnel, powerful emissions of coal combustion products from GRES), but also natural (flat terrain characterized by meadow, more often grassy vegetation) [13]. The reason for the low values is that at the first stages of settling the territories they have obvious advantages (67,9\%) herbaceous species (taproot), which allow to gain a foothold in the ground and form above-ground shoots, but most of the species are annual grasses and die at the end of vegetation [14].

It was established that the area of bare dumps in 2001 at the Bikinsky deposit of brown coal (coal cuts Luchegorsky 1 and Luchegorsky 2) was 4595.92 hectares, and in 2015 1082.64 hectares. Revealed that over the past 15 years have seen overgrowing of about 30 $\%$ of the surface of the dump. Especially intensively, these processes occur on the dumps of the Southern and Northern.

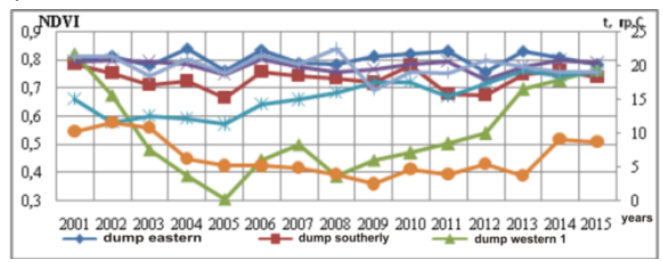

Fig. 4. Indication NDVI and air temperature on the dumps of the Bikinsky brown coal deposit

One of the reasons for the intensive overgrowth of these dumps is a certain temperature regime (fig. 4).

According to the results of the analysis of the space images of the region of studies taken at different times of the year: in winter, in summer, in spring, in autumn (the photographs should be cloudless, but there may be different series and describe different territories), it is possible to construct the dependence of the characteristic values of NDVI on temperatures (t) (fig. 5) and to establish a correlation between the degree of soil degradation and the vegetation response index on air temperature, but this is also how the temperature data vary depending on the region (or are constant values) - a task that is subject to further investigation. 


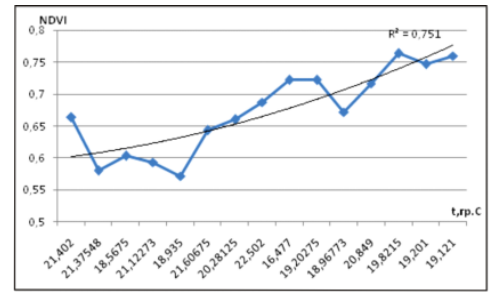

Fig. 5. Dependence of NDVI on temperature

The self-growth of the dumps of the Luchegorsky coal mine is very intensive, therefore there is no need for remediation here. In the stage of stable humus accumulation in soils formed on the dumping rocks, a clearer differentiation of the waste rock to the genetic horizons occurs. This indicates that the emerging ecosystems in the phase of their posttechnogenic development have high regenerative capabilities, there is a formation of soils on loose dumps in a relatively short period of time (up to 30 years).

On self-growth dumps of overburden and enclosing rocks of Raichikhinsky brown coal deposit in the period from 2001-2015. on the basis of the vegetative index NDVI, studies were carried out to analyze the dynamics of the state of vegetation over a 15 -year period (fig. 6).
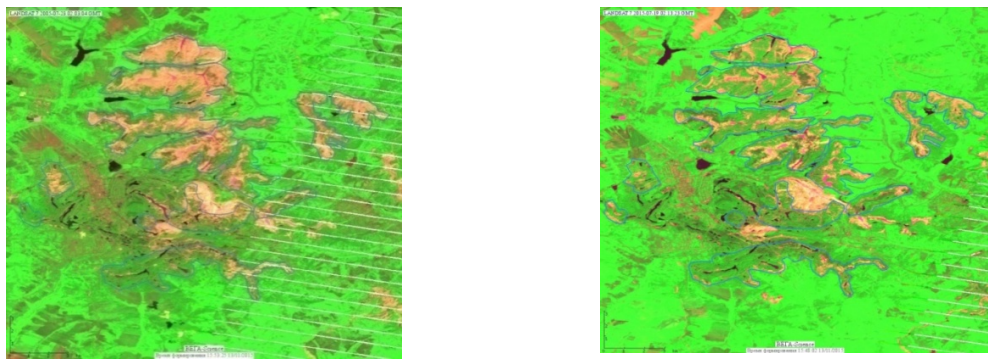

Fig. 6. Dumps of Raichikhinsky brown coal deposit in the system "Vega-Science"

The total open surface of the dumps in 2001 and 2015. made 5565.08 hectares and 1356.58 hectares respectively (calculated in the program QGIS). In this way, the area of the restored territory for 15 years was not less than 4208.5 hectares, which indicates an intensive overgrowth of waste dumps. A stable sustainable growth of biological phytomass and an increase in the vegetative index (fig. 7).

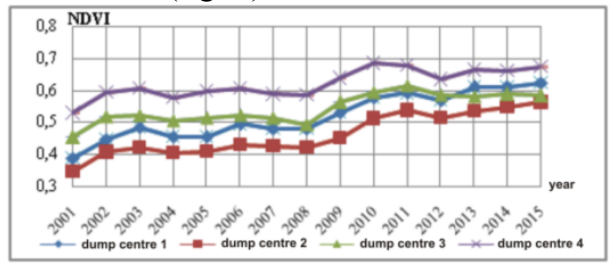

Fig. 7. Dynamics of NDVI secondary phytocenoses of the dumps of Raichikhinsky brown coal deposit

According to our data, the fastest process of overgrowing dumps by vegetation occurs on the western (w-1) and southern dumps (s-1). Perhaps this is due to the predominant South East - Northwest (and vice versa) direction of air flows. The frequency of these winds in Raichikhinsk is about $20 \%$ greater than in neighboring areas.

The nature and intensity of the processes of self-restoration depend entirely on the degree and characteristics of the technogenic changes in the biota during the construction and operation of the extracting enterprise. Based on the results of the study of the dynamics of the species composition of phytocoenoses in rock heaps, it is possible to rationally select the species composition of vegetation that is optimal for local natural and climatic 
conditions for carrying out remediation measures. This will speed up the processes of restoring the natural environment, as well as optimize the costs of environmental protection measures. Thus, it has been established that the properties of technogenic-surface formations differ little from those of self-growing spaces, but the process of natural regeneration proceeds slowly, therefore on disturbed lands it is necessary to combine selfhealing of pioneer vegetation and creation of artificial phytocenoses with the help of remediation measures. All this will contribute to improving the environmental situation and positive dynamics of key environmental indicators within the city of Raichikhinsk.

\section{Conclusion}

The use of remote sensing data in the study of mining dumps provides the opportunity to obtain the following results: to determine the boundaries of dump lands, Identify the areas of denudation and accumulative violations, formed during open coal mining in coal-mining enterprises, and to identify certain large forms of man-made terrain (such as quarries, dumps, sedimentation tanks), with the subsequent calculation of their areas and an estimate of the magnitude of the environmental and economic damage to the environment, i.e. to get an opportunity to give not only a qualitative characteristic of the process of pollution, but also its quantitative evaluation. In the study of dumps of mining enterprises, the zones of anthropogenic transformations of the vegetation cover based on the NDVI spectral index are most reliably identified from remote sensing data, so that the vegetation state can be considered as an indicator of the level of technogenic stress on the natural environment of the study area. This allowed us to determine the zones of self-healing and the causes of intensive overgrowing of the dumps.

\section{References}

1. O. V. Polokhin, Fundamental research, 12, 327 (2014).

2. K. N. Trubetskoi, Ecological problems of subsoil development in the sustainable development of nature and society, 260 (Nauchtekhlitizdat, 2003).

3. S. I. Im, V. I. Kharuk, , Geofizicheskie protsessy i biosfera, 14:1, 53 (2015).

4. E. V. Pavlova, M. L. Makhrova, G. Yu. Yamskikh, Zhurnal Sibirskogo federalnogo univesriteta. Seriya: Tekhnika i tekhnologii, 8:6, 706 (2015).

5. L P. Shoo, P. Scarth, S. Schmidt, K. A., Restoration Ecology, 21:4, 481 (2013).

6. K. V. Myachin, Geoinformatics, 2, 2 (2016).

7. Quantum GIS [Electronic resource]. - Access mode: http://freesoft.ru/quantum_gis

8. L. Lovgren, T. Hedlung, M. Lindegren, Ehkologicheskaya strategiya razvitiya gornodobyvayushchej otrasli - formirovanie novogo mirovozzreniya $\mathrm{v}$ osvoenii prirodnyh resursov, 2, 72 (2015).

9. Site with archive of data on radar probing of the Earth's surface SRTM3 [Electronic resource]. - Access mode: http://dds.cr.usgs.gov/srtm/version2_1/SRTM3/

10. H. J. Bowen, Environmental chemistry of the elements, 333 (N.Y.: Acad. Press, 1979)

11. V. N. Oparin, Physical and technical problems of mining, 6, 190 (2014).

12. J. W. Rouse, Monitoring the vernal advancement and retrogradation (greenwave effect) of natural vegetation, 371 (NASA/GSFC Type III Final Report, Greenbelt, 1974).

13. N. M. Kostenkov, V. I. Oznobikhin, Stimulation of the processes of self-growth of dumps of brown coal cuttings in the south of the Far East, 131 (Izd-vo Okarina, 2013).

14. L. N. Purtova, L. N. Shchapova, I. V. Komachkova, Vestnik of the Far East Branch of the Russian Academy of Sciences, 4, 62 (2010). 